Pedagogical Research, 1:2 (2016), 53

ISSN: 2468-4929

\title{
Values in the Mathematics Classroom: Supporting Cognitive and Affective Pedagogical Ideas
}

\author{
Wee Tiong Seah ${ }^{1 *}$ \\ ${ }^{1}$ Melbourne Graduate School of Education, The University of Melbourne, Australia \\ *Corresponding Author: wt.seah@unimelb.edu.au
}

Citation: Seah, W.T. (2016) Values in the Mathematics Classroom: Supporting Cognitive and Affective Pedagogical Ideas, Pedagogical Research, 1:2 (2016), 53.

doi: http://dx.doi.org/10.20897/lectito.201653

Published: November 15, 2016

\begin{abstract}
Values are the personal convictions which one finds important. Three different aspects which are associated with mathematics education differently are identified, namely, values through mathematics education, values of mathematics education, and values for mathematics. These are paired with Bishop's (1996) conceptions of general educational, mathematical, and mathematics educational values respectively. This article provides examples of what these values might look like in different classroom scenarios, and how values as a volitional construct scaffolds cognitive and affective developments in mathematics learning. Implications for teachers include the need to assess validly what students value, and the need to better understand how teachers practise values alignment within their own classrooms. In so doing, appropriate valuing by teachers and their students can serve its purpose of fostering mathematical understanding and/or performance.
\end{abstract}

Keywords: Values, values alignment, values assessment, volition, WIFI Study

\section{INTRODUCTION}

Many education systems expect ethical and moral values to be inculcated amongst their young citizens through the various school subjects, including mathematics. These would include Australia (Australian Curriculum, Assessment and Reporting Authority, 2013b) and Singapore (Wong, Lee, Kaur, Foong, \& Ng,2009). Additionally, and relatively unknown to many teachers, values also play a part in enhancing students' understanding and/or performance in mathematics (Movshovitz-Hadar, \& Edri, 2013). Consider the following scenario which one may find in classrooms around many parts of the world:

Betty is a high school student, and she has been wondering how the concepts and skills she had learnt would be of any use in her daily life. As such, her attitude to the subject had not been very positive. She was certainly not enjoying mathematics lessons, and, she often found herself not understanding her mathematics teacher's explanations readily. Rather, her peers and her home tutor have been of help in this context. Yet, despite these affective and cognitive barriers, Betty knew that she has to work hard on mathematics. She understood the importance of doing well in it in order to optimise her chance of studying her preferred subjects later on in high school, as well as to get into university. Getting into university was crucial, for she was aware that she would be the first person in her extended family to do so, and her parents had been working multiple jobs to afford an education for Betty in an independent school as well as a home tutor. Not doing well in mathematics was not an option for Betty, and she was determined to overcome any barrier to achieve in the subject. 
Although most if not all students desire to achieve in their studies, not every student value achievement enough to possess the will and determination to do well in mathematics, especially when a barrier or obstacle (e.g. 'bad' teacher explanations, abstract mathematical ideas) appears in the process of learning it. For Betty in the scenario above, the importance - and valuing - she placed on achievement had given her a sense of will and determination to do well in mathematics, despite a generally negative attitude to the subject and despite her not always readily understanding her teacher's explanations. Indeed, a recent analysis of what 1386 students in mainland China, Hong Kong and Taiwan value in their mathematics learning (Zhang, Barkatsas, Law, Leu, \& Seah, submitted) not only echoed the TIMSS 2011 (Mullis, Martin, Foy, \& Arora, 2012) findings that the high performing East Asian students possessed the least positive feelings towards mathematics, it also revealed that across these three regions, the students had found it most important to achieve. Thus, it seems that appropriate valuing might arm students with a powerful force to overcome barriers to success. If this is so, it is worthwhile to explore how we can tap into the things students and teachers value in mathematics learning and teaching respectively to bring about more effective mathematics education in schools.

\section{Three different ways of considering values in mathematics education}

Values and mathematics education may be regarded as associating with each other in three different aspects, namely, values through mathematics education, values of mathematics education, and values for mathematics education.

As teachers, we are often reminded of our role as an educator of human character, not just as a teacher of subject content (see, for example, Pantić \& Wubbels, 2012). Indeed, teachers play the roles of both moral agents and values educators (Campbell, 2006). Forster (2012) traced the development of the kinds of values teachers in Australia have been expected to teach:

Lovat and McLeod (2006) argue that the nineteenth century saw the Australian teacher's role established as a fundamentally moral one. These expectations have since expanded towards multiculturalism and social justice. Professional authorities now expect "specific attitudes to issues of gender, race, the environment, and human rights" (Glegg, 2003, p. 18). (p. 2)

In this perspective, classroom teachers advocate and teach the valuing of, for examples, fairness and buman rights through the ways they weave related discussions into their lesson planning and execution. This aspect of associating values to mathematics education is clearly emphasised in most if not all mathematics curriculum statements. For example, the Australian Curriculum has the expectation that students are taught seven general capabilities, which include personal and social capability, etbical understanding, as well as intercultural understanding (ACARA, 2013a, n.p.). Here, we are concerned with 'values through mathematics education'.

On the other hand, socio-politico and cultural values are also inadvertently embedded in mathematics, perhaps through educational policies and through the societal norms. Bishop (1988) and Ernest (2009) had regarded mathematics as value-laden and having its own social responsibilities. In particular, Bishop (1988) conceptualised that Western mathematics value rationalism and objectism, control and progress, and openness and mystery. The Australian Curriculum demonstrates this aspect of valuing when it emphasises that it "values Aboriginal and Torres Strait Islander histories and cultures. It provides opportunities for students to appreciate that Aboriginal and Torres Strait Islander societies have sophisticated applications of mathematical concepts" (ACARA, 2013a, n.p.). In Western societies, there is often the association of mathematics to the valuing of being able to compute (as opposed to visualising, for example). This aspect of mathematics education might be called 'values of mathematics education'.

There is also a third aspect of values in the context of mathematics education. This third aspect might be called 'values for mathematics education'. It draws our attention to ways in which what is valued by teachers and students might be harnessed to optimise mathematical understanding and competence, as mentioned at the beginning of this article. In this context,

values in mathematics education are the convictions which an individual has internalised as being the things of importance and worth in the learning and teaching of mathematics. What an individual values defines for her/him a window through which s/he views the nature of mathematics, and how it can be best learnt or taught. Valuing provides the individual with the will and determination to maintain any course of action chosen in the learning and teaching of mathematics. They regulate the ways in which a learner's/teacher's cognitive skills and emotional dispositions are aligned to learning/teaching. (Seah \& Andersson, in press) 


\section{Harnessing the values for mathematics education}

In this third aspect, teachers harness what is valued by the classroom community and inculcate other appropriate values as needed with the aim of fostering student understanding of and/or performance in mathematics. For example, when teachers recognise students' valuing of play in negotiating conceptual understanding, and subsequently facilitate exploratory activities with manipulatives in their lessons, they are harnessing the valuing of play to optimise student learning. On the other hand, a teacher may value play as a pedagogical approach to conceptual understanding, thus inculcating it amongst students by structuring exploratory activities in the planned lessons.

The example above with the valuing of play illustrates how values facilitate student mastery of mental skills and strategies (e.g. mathematical understanding) and foster positive affective states (e.g. confidence). As a volitional variable, values scaffold cognitive development and affective growth.

The nature of this third aspect of valuing is different from the previous aspects. They are often not the ethical or moral values which students are expected to embrace. They also do not reflect what is valued in the discipline, the institution, or the wider society. Rather, these values for mathematics education are considered to facilitate effective mathematics learning, and as such they are reflective of personal preferences (that of teachers and students).

\section{What do values look like?}

The three aspects of values serving different functions in relation to mathematics education as discussed above can be compared to Bishop's (1996) categories of values in the school mathematics classroom. These categories are, namely, mathematical values, mathematics educational values, and general educational values. Briefly, mathematical values are the things which mathematics as a discipline finds important. The six values proposed by Bishop (198), in complementary pairs of rationalism and objectivism, control and progress, and openness and mystery, are examples of such mathematical values. These could be regarded as the values of mathematics education.

Mathematics educational values are those which are related to the pedagogy of the subject, such as practice and group work. These are the values for mathematics education, in the sense that their valuing takes place in the context of activities and decisions that are executed to enhance mathematics teaching and learning. Indeed, one may say that a student may not find practice important in studying for History or Science, but $\mathrm{s} /$ he may well value it in mathematics, so that his/her skill continues to be honed.

On the other hand, general educational values refer to those which are regarded as important in school education generally, and which are taught through different school subjects, including mathematics. Examples of general educational values are creativity and respect. These would correspond to the aspect of values through mathematics education.

A range of things are valued at any time during any mathematics lesson. The scenario below provides an example.

In a lesson on place value, Kathryn had given each of her students a piece of A4-size card. They were given time to draw (and decorate) their own favourite numeral on their given piece of card, after which three students were selected to come to the front of the class with their cards. These three cards were held to their chests so that they were visible to the rest of the class. The three students' task was to arrange themselves in a straight line such that the cards would represent the largest possible three-digit number. They were also expected to explain to the class why they had chosen to arrange themselves in the particular order. This process was then repeated with a few other groups of three students.

By training her students to listen to their peers' explanation, Kathryn was advocating the valuing of respect. This scenario also exemplifies her purposeful incorporation of the valuing of openness (see Bishop, 1988) and of fun in the lesson to promote student understanding of the concept of multiple-digit place values. By nominating groups of three students to defend publicly their composition of three-digit numbers, Kathryn was inculcating the valuing of openness in western mathematics (see Bishop, 1988), in which mathematicians are required to present and justify their findings to the scientific community. Here, the valuing of openness through learning tasks as identified in the scenario can help students to appreciate the role of public sharing and discussions in facilitating understanding.

Kathryn could have discussed concepts related to place value directly to the students. Yet, she had chosen to devote time to conduct a classroom activity such as this, through which Kathryn hoped that the students would be immersed in better learning in a fun environment. Not surprisingly, pre-service teachers in Australia and 
Singapore had nominated fun most frequently as a value associated with particularly effective mathematics learning when they were students themselves in schools (Seah \& Ho, 2009).

Indeed, researching what students value in studies such as Law, Wong and Lee (2011) and Seah and Ho (2009) have provided evidence that there is a range of mathematics educational values which facilitate effective learning. Zhang, Barkatsas, Law, Leu and Seah (submitted) analysed what 1386 Grades 5/6 students in mainland China, Hong Kong, and Taiwan valued in mathematics learning. Principal component analysis had revealed that six similar values were embraced in each of the East Asian mathematics education systems, namely achievement, relevance, practice, communication, information and communication technologies [ICT] and feedback, although the relative order of emphasis was different amongst mainland China, Hong Kong, and Taiwan. Equally significantly, statistically significant differences amongst the three regions were found in the valuing of each of these values for mathematics education. For example, although all three regions valued achievement the most, mainland Chinese students appeared to place more emphasis on it than their peers in Taiwan.

\section{What might be the outcomes of valuing something in mathematics education?}

As we saw in the scenario involving Betty earlier in the article, the valuing that takes place translates to will and determination, which drove Betty to take on particular courses of action and which sustained this course of action in the face of obstacles and barriers. If a teacher does not value, say, ICT, no amount of professional development courses and no amount of confidence with the manipulation of the CAS calculator is going to lead to teacher meaningful harnessing of ICT in mathematics lessons. Should institutional policies demand the use of ICT in mathematics classrooms, this teacher might include ICT superficially in the lessons (in which case the students would probably sense their teacher's lack of commitment anyway), or s/he might simply ignore the policies. On the other hand, for any teacher who values ICT in the context of teaching mathematics, s/he will do whatever it takes to upskill himself/herself and further reinforce the positive affective dispositions associated with the use of ICT tools to support learning.

Emphasising the role of values in facilitating effective learning / teaching of mathematics by students / teachers does not imply that the mental and emotional aspects of pedagogical ideas are forgotten. (Primary school) teachers will still find it useful to facilitate students' understanding of, say, the two meanings of division (i.e. partition and quotation), to promote problem-solving capacity, and to foster student efficacy and motivation, amongst other things. Students of mathematics will continue to need relevant cognitive skills and affective states to do mathematics well, and teachers likewise will still need both these types of capacities to do their job well. What is new knowledge, however, is that teachers can now understand more - and regulate - what they value in their professional practice, so that these in turn scaffold the development of mental and affective capacities to optimise mathematics understanding and performance.

\section{Implications for teachers}

How then do we go about facilitating students' appropriate valuing such that it helps them to study mathematics more effectively? The first step would be to have a good idea of what is currently being valued by students. There are several ways of achieving this, including the student interview method in which students are asked verbally what is important to them whenever they learn mathematics well.

An efficient way of finding out what students value is through the administering of an appropriate questionnaire. The 'What I Find Important [WIFI] in mathematics learning' questionnaire (see Appendix for the items in the English version) is one such instrument which had been designed and subsequently validated crossculturally for this task specifically. By indicating the extent to which s/he values features of mathematics learning such as 'looking for different ways to find the answer' (item 15), and by positioning herself/himself between the valuing of 'how the answer to a problem is obtained' and 'what the answer to a problem is' (item 66), what a student finds important can be mapped out efficiently.

Knowing what his/her students value in their mathematics learning experiences, a teacher can identify the areas which are strongly emphasised, at the same time discovering what might not be valued yet. How do these values facilitate or impede understanding? How do they facilitate or impede performance? What could the students value more so that particular cognitive skills or affective states can be better fostered?

In this way, teachers' lesson planning, execution and assessment can be more customised and holistic. While the teacher's practice can now better take into account the cultural uniqueness of what the students value, it is also holistic in the sense that we are now taking into consideration all three aspects of students' learning, that is, volitional, which supports the cognitive and affective. 
Yet, in a classroom setting, the reality is that the coming together of teachers and the many students implies that a range of values are advocated and interacting with one another at the same time. What a teacher values is certainly an important aspect of the classroom discourse too. Not all these students and teachers' values agree with one another, of course. How do teachers deal with these value differences and value conflicts? What are the approaches which might be particularly useful? These are questions to which we currently do not have ready answers to, and indeed, they describe the focus of an ongoing research study to help us understand better how effective teachers master the craft of values alignment with their own classes, to bring about effective student understanding of and performance in their practice. This is especially significant for the subject of school mathematics, one which is often used as a gatekeeper to access to further studies, but which remains as a subject that relatively few students like and/or master. The values approach might just provide the boost to the effectiveness of current and future cognitive and affective pedagogical ideas for mathematics.

\section{REFERENCES}

Australian Curriculum Assessment and Reporting Authority.[ACARA]. (2013a). Mathematics: Diversity of learners. Retrieved June 11, 2013, from http://www.australiancurriculum.edu.au/Mathematics/Diversity-of-learners

Australian Curriculum Assessment and Reporting Authority [ACARA]. (2013b). The Australian Curriculum v5.1: Mathematics. http://www.australiancurriculum.edu.au/Mathematics/Content-structure

Bishop, A. J. (1988). Mathematical enculturation: A cultural perspective on mathematics education. Dordrecht, The Netherlands: Kluwer Academic Publishers.

Bishop, A. J. (1996, June 3-7). How should mathematics teaching in modern societies relate to cultural values --- some preliminary questions. Paper presented at the Seventh Southeast Asian Conference on Mathematics Education, Hanoi, Vietnam.

Campbell, E. (2006). Ethical knowledge in teaching: A moral imperative. Education Canada, 46(4), 32-35.

Clarkson, P., Seah, W. T., \& Bishop, A. (2010). Mathematics wellbeing and teacher education. In R. Toomey, T. Lovat, N. Clement \& K. Dally (Eds.), Teacher education and values pedagogy: A student wellbeing approach (pp. 179194). New South Wales, Australia: David Barlow Publishing.

Ernest, P. (2009). Values and the social responsibility of mathematics. In P. Ernest, B. Greer \& B.

Sriraman (Eds.), Critical issues in mathematics education (pp. 207-216). Missoula, MT: Information Age Publishing.

Forster, D. (2012). Codes of ethics in Australian education : Towards a national perspective. The Australian Journal of Teacher Education, 37(9), 1-17.

Law, H. Y., Wong, N. Y., \& Lee, L. N. Y. (2011). The Third Wave studies of values in effective mathematics education: Developing students' mathematical autonomy in classroom learning. Mathematics Educator, 13(1), 70-84.

Movshovitz-Hadar, N., \& Edri, Y. (2013). Enabling education for values with mathematics teaching. In C. Margolinas (Ed.), Task design in mathematics education: Proceedings of ICMI Study 22 (pp. 377-388). Oxford, UK: Oxford

Mullis, I. V. S., Martin, M. O., Foy, P., \& Arora, A. (2012). TIMSS 2011 international results in Mathematics. Amsterdam, The Netherlands: International Association for the Evaluation of Educational Achievement (IEA).

Pantić, N., \& Wubbels, T. (2012). The role of teachers in inculcating moral values: Operationalisation of concepts. Journal of Beliefs and Values, 33(1), 55-69. doi: 10.1080/13617672.2012.650030

Seah, W.T., \& Andersson, A. (in press). Beyond cognition and affect: Valuing as a volitional variable in mathematics education. In A. Bishop, T. Barkatsas \& H. Tan (Eds.), Rethinking diversity in mathematics education: Towards inclusive practices. NY, Springer.

Seah, W.T., \& Ho, S. Y. (2009). Values operating in effective mathematics lessons in Australia and Singapore: Reflections of pre-service teachers. In M. Tzekaki, M. Kaldrimidou \& H. Sakonidis (Eds.), Proceedings of the 33 rd conference of the International Group for the Psychology of Mathematics Education (Vol. 5, pp. 57-64). Thessaloniki, Greece: PME.

Wong, K.Y., Lee, P.Y., Kaur, B., Foong, P.Y., \& Ng, S.F.. (2009). Introducing the landscape of the Singapore mathematics education journey. In K. Y. Wong, P. Y. Lee, B. Kaur, P. Y. Foong \& S. F. Ng (Eds.), Mathematics education: The Singapore journey (pp. 1-9). Singapore: World Scientific.

Zhang, Q., Barkatsas, T., Law, H. Y., Leu, Y-C, \& Seah, W.T. (submitted). What primary students value in mathematics learning: A comparative analysis among the Chinese mainland, Hong Kong, and Taiwan. International Journal of Science and Mathematics Education. 


\section{Appendix}

'What I Find Important [WIFI] in Mathematics Learning' - Student questionnaire

[This version is not formatted and condensed, to show the content only]

Instructions:

Dear student,

- There are no right or wrong answers to the questions in this survey

- Since everyone is different, it is important that your responses reflect your personal views.

- Your responses will be kept confidential.

- Please respond to all items.

- If you had completed this survey recently, please do not fill this in again.

- Thank you for your time!

Section A

For each of the items below, tick a box to tell us how important it is to you when you learn mathematics.

[Each of the following choices is associated with a box: Absolutely important / Important / Neither important nor unimportant / Unimportant / Absolutely unimportant]

1. Investigations

2. Problem-solving

3. Small-group discussions

4. Using the calculator to calculate

5. Explaining by the teacher

6. Working step-by-step

7. Whole-class discussions 
8. Learning the proofs

9. Mathematics debate

10. Relating mathematics to other subjects in school

11. Appreciating the beauty of maths

12. Connecting maths to real life

13. Practising how to use maths formulae

14. Memorising facts (eg Area of a rectangle = length X breadth)

15. Looking for different ways to find the answer

16. Looking for different possible answers

17. Stories about mathematics

18. Stories about recent developments in mathematics

19. Explaining my solutions to the class 
20. Mathematics puzzles

21. Students posing maths problems

22. Using the calculator to check the answer

23. Learning maths with the computer

24. Learning maths with the internet

25. Mathematics games

26. Relationships between maths concepts

27. Being lucky at getting the correct answer

28. Knowing the times tables

29. Making up my own maths questions

30. Alternative solutions

31. Verifying theorems / hypotheses 
32. Using mathematical words (eg angle)

33. Writing the solutions step-by-step

34. Outdoor mathematics activities

35. Teacher asking us questions

36. Practising with lots of questions

37. Doing a lot of mathematics work

38. Given a formula to use

39. Looking out for maths in real life

40. Explaining where rules / formulae came from

41. Teacher helping me individually

42. Working out the maths by myself

43. Mathematics tests / examinations

(C) 2016 by author/s 
44. Feedback from my teacher

45. Feedback from my friends

46. Me asking questions

47. Using diagrams to understand maths

48. Using concrete materials to understand mathematics

49. Examples to help me understand

50. Getting the right answer

51. Learning through mistakes

52. Hands-on activities

53. Teacher use of keywords (eg 'share' to signal division; contrasting 'solve' and 'simplify')

54. Understanding concepts / processes 
55. Shortcuts to solving a problem

56. Knowing the steps of the solution

57. Mathematics homework

58. Knowing which formula to use

59. Knowing the theoretical aspects of mathematics (eg proof, definitions of triangles)

60. Mystery of maths (eg 111111 111x111 $111111=12345678987654$ 321)

61. Stories about mathematicians

62. Completing mathematics work

63. Understanding why my solution is incorrect or correct

64. Remembering the work we have done

65. Comments (if any): 


\section{Section B}

For each pair of phrases below, mark on the line segment to indicate how more important one phrase is to you in your maths learning than the other phrase.

If you mark in the middle, it would mean that both phrases are equally important to you.

Example (non-maths)

Watching a movie _ _

66. How the answer to a problem is obtained vs

What the answer to a problem is

67. Feeling relaxed or having fun when doing maths vs

Hardwork is needed when doing maths

68. Leaving it to ability when doing maths vs

Putting in effort when doing maths

69. Applying maths concepts to solve a problem vs

Using a rule / formula to find the answer

70. Truths and facts which were discovered vs

Mathematical ideas and practices we normally use in life

71. Someone teaching and explaining maths to me vs

Exploring maths myself or with peers / friends / parents

72. Remembering maths ideas, concepts, rules or formulae vs

Creating maths ideas, concepts, rules or formulae

73. Telling me what a triangle is vs

Letting me see concrete examples of triangles first, so that I understand the properties of triangles 
74. Demonstrating and explaining maths concepts to others (e.g. proofs)

Keeping mathematics magical / mystical

75. Using maths to predict / explain events, that is, to stay in control vs Using maths for development / progress

76. Comments (if any):

Section C

Imagine that you are the school principal, and you are now looking for a teacher for your school who can teach mathematics very well.

What are the $\mathbf{3}$ most important features of a mathematics lesson you want to see in the successful applicant's mathematics teaching? (Take a moment to think. You can change your answers anytime before you submit this questionnaire.)

77. Most important feature:

78. Second most important feature:

79. Third most important feature:

80. I selected these features because:

\section{Section D}

Please tell us something about yourself.

81. I am currently studying in (please select one country/region).

82. My school is located in this city/town/suburb/village: 
83. My school is a (please select one school type)

84. My school is co-educational (boys and girls) / girls only / boys only

85. In my class, maths is taught in language.

86. At home, I speak mainly language.

87. My ethnicity is (please select one).

88. I was born in this country:

89. If you were born overseas, when did you come to your current country?

90. My age is

91. My grade level at school is:

92. Gender (please select one).

93. I do well in mathematics at school.

Strongly agree / Agree / Disagree / Strongly disagree / Not sure 